\title{
Relevance of MICA Alleles Matching Rate and Posttransplant Rejection in Clinical LRD Organ Transplantations
}

\author{
Liang He1, Gang Ji², Zhang Zhang², Chunsheng Xu², Weizhong Wang², Boquan Jin², \\ Guanglong Dong ${ }^{3 *}$ \\ ${ }^{1}$ Department of General Surgery, Lanzhou Military District Hospital in Urumqi, Urumqi, China \\ ${ }^{2}$ Department of Gastrointestinal Surgery, State Key Laboratory of Cancer Biology and Xijing Hospital of \\ Digestive Diseases, Fourth Military Medical University, Xi'an, China \\ ${ }^{3}$ Department of General Surgery, The General Hospital of the People's Liberation Army, Beijing, China \\ Email: heliangfmmu@sina.com
}

Received 24 December 2014; accepted 10 January 2015; published 16 January 2015

Copyright (C) 2015 by authors and Scientific Research Publishing Inc.

This work is licensed under the Creative Commons Attribution International License (CC BY).

http://creativecommons.org/licenses/by/4.0/

(c) (i) Open Access

\begin{abstract}
Objective: Recipients usually undergo posttransplant rejection in HLA-identical transplantations. Recent studies have shown that MHC class I related chain A (MICA) has been found to be associated with allograft survival. The goal of this study is to investigate the correlation between matching rate of MICA alleles and posttransplant rejection in clinical living related donor transplantation (LRD) organ transplantations. Methods: Twenty pairs of blood samples were detected for HLA/MICA matching through polymerase chain reaction with sequence specific primers and for anti-MICA Abs using Luminex. At the same time, pathologic biopsies of all recipients were diagnosed and classified into different levels by the unified standard. Univariate Spearman's analysis was established. Log-Rank analysis was performed twice, and Kaplan-Meier survival curves were generated to assess the relationship between MICA matching rates and posttransplant rejection in living-related donor transplantations. Results-The result showed that HLA matching of all recipients and donors were identical, whereas MICA matching was not. There was statistical difference between pathological classification and survival $(P<0.05)$. The development of Abs to MICA was strongly associated with posttransplant rejection. Conclusions: Recipients with higher MICA matching rates with their donors had lower pathologic classifications and were more likely to survive longer. Lower graft survival and more rejection episodes were observed among recipients with lower MICA matching rates with donors. Aside from HLA matching, the MICA matching rate could be an important prognostic index for LRD transplantations.
\end{abstract}

${ }^{*}$ Corresponding author.

How to cite this paper: He, L., et al. (2015) Relevance of MICA Alleles Matching Rate and Posttransplant Rejection in Clinical LRD Organ Transplantations. International Journal of Clinical Medicine, 6, 33-43.

http://dx.doi.org/10.4236/ijcm.2015.61005 


\section{Keywords}

\section{MHC, HLA, MHC Class I Related Chain A (MICA), Polymerase Chain Reaction (PCR), Living Related Donor Transplantation (LRD)}

\section{Introduction}

The HLA matching rate between donors and recipients is correlated with posttransplantation rejection and survival, and rejection can often be attributed to HLA mismatch. However, studies have also shown that transplant failure can occur in HLA-identical living-related donor (LRD) transplantations, suggesting the need to identify non-HLA antigens that lead to graft failure. Successive studies have indicated that non-HLA antigens contribute substantially to transplant failure in HLA-identical donor transplants [1]-[3].

MHC class I related chain A (MICA) is a non-classical Class I gene with 67 MICA alleles found in the major histocompatibility complex (MHC) in tight linkage disequilibrium with the human leukocyte antigen-B gene locus (HLA-B) [4]. Unlike classical class I molecules, the MICA protein without $\beta 2$-microglobulin binding is expressed on the cell surface of endothelial cells, which makes this polymorphic molecule a target for both cellular and humoral immune responses. MICA has many alleles and its diversity resides in different races and ethnic groups [5]. The polymorphic MICA gene can inducing graft versus host reaction (GVHR) or host versus graft reaction (HVGR) in transplantation, and a series of studies have shown that antibodies to this highly polymorphic molecule have been detected in patients who have undergone transplantations [6]-[9]. Moreover, allograft-induced MICA antibodies have been implicated in transplant failure [10]-[12]. Frequently, patients who have experienced posttransplant rejection had more HLA and MICA antibodies than those with functioning grafts [13].

Presently, there are no reports of MICA alleles matching prior to LRD transplantations. Therefore, the MICA matching rates between recipients and donors we studied to evaluate their potential impact on posttransplant rejection in HLA-identical LRD organ transplantations.

\section{Materials and Methods}

\subsection{Patients and Specimens}

With the approval of the Fourth Military Medical University Institutional Review Board, a retrospective chart review of 20 LRD organ transplantations was performed at Xijing Hospital, Fourth Military Medical University. Written informed consent was obtained from all participants.

Four cases of LRD small intestine transplantations performed between 1999 to 2006 were enrolled in the current study, including 3 cases of short gut syndrome (including the first case of LRD small intestine transplantation in China) and 1 case of posttraumatic enteric necrosis (two recipients were deceased and their pathological sections were taken as the research targets). At the same time, 6 cases of LRD liver transplantations and 10 cases of LRD kidney transplantations performed between 2006 and 2007 were also enrolled, including 4 cases of cirrhosis, 2 cases of hepatolenticular degeneration without hepatocellular carcinoma, and 10 cases of renal failure or uremia without renal carcinoma. All 20 pairs of donors and recipients were parent-child, except for one case of LRD kidney transplantation (uncle-child). Patients' details are displayed in Table 2.

All patients had negative donor-specific complement-dependent cytotoxicity (CDC) cross matches before the transplantations. All 20 donors were in good health and without specific underlying diseases. Recipients with posttransplant rejection episodes were treated with standard immunosuppression. Twenty pairs of donor-recipient whole blood specimens, and 20 recipient pathologic sections were taken for HLA/MICA matching and pathologic diagnosis after the transplantations in the present study.

\subsection{HLA Matching}

DNA was extracted from whole blood samples using HLA-Morgantm ABDR SSP Kit (Texas BioGene, Inc.) according to the manufacturer's instructions. DNA sequencing for HLA matching was performed for the alleles HLA-A, HLA-B, and HLA-DR using the polymerase chain reaction with sequence specific primers (PCR-SSP) 
technique. Each reaction, containing 20 - 150 ng genomic DNA was amplified in a final volume of $8 \mu \mathrm{L}$, which contained PCR buffer $(8 \mathrm{M}, 6 \mu \mathrm{L})$ and Taq DNA polymerase $(5 \mathrm{U} / \mu \mathrm{L}, 0.06 \mu \mathrm{L})$. The PCR cycles for amplification were performed after forced denaturation at $96^{\circ} \mathrm{C}$ for $2.5 \mathrm{~min}$ (PE-9600 or PE-9700), with 33 cycles at $96^{\circ} \mathrm{C}$ for $15 \mathrm{~s}, 65^{\circ} \mathrm{C}$ for $60 \mathrm{~s}, 95^{\circ} \mathrm{C}$ for $15 \mathrm{~s}, 62^{\circ} \mathrm{C}$ for $50 \mathrm{~s}, 72^{\circ} \mathrm{C}$ for $30 \mathrm{~s}$, and final holding at a constant $4^{\circ} \mathrm{C}$. The amplification products $(6 \mu \mathrm{L})$ were electrophoresed $(2 \%$ gel and $0.5 \times$ TBE buffer [pH 8.0]) at $8-10 \mathrm{~V} / \mathrm{cm}$ for $5-7$ min in the same order, and were observed under an ultraviolet transilluminator thereafter.

\subsection{MICA Matching}

Genomic DNA from peripheral blood was extracted using TIANamp Blood kit as recommended. DNA extraction from paraffin sections, for the two deceased LRD small intestine transplantations, was performed following Goelz's method. Eight frequent MICA genotypes (MICA*008, MICA*010, MICA*002, MICA*012, MICA* 007, MICA*004, MICA*017, and MICA*049) consisting of 13 alleles in the Chinese Han population, were chosen as the study targets. Among them, MICA*002 contained 3 alleles (MICA*00201, MICA*00202, and MICA*00203). MICA*004, MICA*007, and MICA*012 contained 2 alleles each (MICA*00401, MICA*00402; MICA*00701, MICA*00702; MICA*01201, MICA*01201). The remaining 4 MICA genotypes have only one allele each. The frequency of the 8 chosen MICA alleles covered over $95 \%$ of all MICA alleles in the Chinese Han population (Table 1).

Table 1. Primers' sequence of selected 13 MICA alleles.

\begin{tabular}{|c|c|c|c|}
\hline MICA alleles & Primers' name & Primers' code & Primers' sequence \\
\hline \multirow[t]{2}{*}{ MICA*008 } & upstream & $663 \mathrm{C}$ & 5/-GCCTCAGAGGGCAACATC-3/ \\
\hline & downstream & $952 C^{\prime}$ & 5/-ATAACAAAAATAGCAGCAGCC-3/ \\
\hline \multirow[t]{2}{*}{$\mathrm{MICA} * 010$} & upstream & $85 \mathrm{C}$ & 5/-CAGAGCCCCACAGTCTTCC-3/ \\
\hline & downstream & $454 C^{\prime}$ & 5/-TCTGGAGGACTGGGGCAC-3/ \\
\hline \multirow[t]{2}{*}{ MICA*00201 } & upstream & $692 \mathrm{~A}$ & 5/-GCAGGGCTTCTGGCTTCTA-3/ \\
\hline & downstream & 1002G' & 5/-TTCTTCTTACAACAACAGACG-3/ \\
\hline \multirow[t]{2}{*}{ MICA*00202 } & upstream & $146 \mathrm{~T}$ & 5/-CAGGGTTTCTCGCTGAGGT-3/ \\
\hline & downstream & 1002G' & 5/-TTCTTCTTACAACAACAGACG-3/ \\
\hline \multirow[t]{2}{*}{ MICA*00203 } & upstream & $341 \mathrm{~A}$ & 5/-AAGGCTTGCATTCССТССА-3/ \\
\hline & downstream & 1002G' & 5/-TTCTTCTTACAACAACAGACG-3/ \\
\hline \multirow[t]{2}{*}{ MICA*01201 } & upstream & 139CA & 5/-GTGCAGTCAGGGTTTCTCA-3/ \\
\hline & downstream & $536 A^{\prime}$ & 5/-CTGCATGCATAGCGTGATAGA-3/ \\
\hline \multirow[t]{2}{*}{ MICA*01202 } & upstream & $237 \mathrm{~T}$ & 5/-CAGAAGATGTCCTGGGAAAT-3/ \\
\hline & downstream & $536 A^{\prime}$ & 5/-CTGCATGCATAGCGTGATAGA-3/ \\
\hline \multirow[t]{2}{*}{ MICA*00701 } & upstream & $109 \mathrm{~T}$ & 5/-TAACCTCACGGTGCTGTCCT-3/ \\
\hline & downstream & MM642A' & 5/-GTTGCCCTCAAAGGCCTCA-3/ \\
\hline \multirow[t]{2}{*}{ MICA*00702 } & upstream & $642 \mathrm{~T}$ & 5/-GTGAATGTCACCCGCAGT-3/ \\
\hline & downstream & 820G' & 5/-ССТСТGСТССТСТССТTG-3/ \\
\hline \multirow[t]{2}{*}{ MICA*00401 } & upstream & $611 \mathrm{G}$ & 5/-GCGTAGTCCTGAGGAGAAG-3/ \\
\hline & downstream & $713 G^{\prime}$ & 5/-CCCATCCTGACGCCAGG-3/ \\
\hline \multirow[t]{2}{*}{ MICA*00402 } & upstream & $109 \mathrm{~T}$ & 5/-TAACCTCACGGTGCTGTCCT-3/ \\
\hline & downstream & $433 C^{\prime}$ & 5/-TCСАТTССТСАGTСТССАС-3/ \\
\hline \multirow[t]{2}{*}{ MICA*017 } & upstream & 139CG & 5/-TGTGCAGTCAGGGTTTCTCG-3/ \\
\hline & downstream & $341 C^{\prime}$ & 5/-СТCACAGACССТААТСТССС-3/ \\
\hline \multirow[t]{2}{*}{ MICA*049 } & upstream & $10820 \mathrm{~A}$ & 5/-GAGGGTCAGGAGAGGCCA-3/ \\
\hline & downstream & $1088 A^{\prime}$ & 5/-GCATCCCTGTGGTCACTCA-3/ \\
\hline \multirow[t]{2}{*}{ Control } & upstream & hghsen & 5/-CAGTGCСТTCССААССАТTСССТТА-3/ \\
\hline & downstream & hghanti & 5/-ATCCACTCACGGATTTCTGTTGTGT-3/ \\
\hline
\end{tabular}

Control: Human growth hormone peptide. 
MICA typing was performed with the PCR-SSP technique. A total of 390 PCRs were used for the MICA alleles. Each reaction, containing $10 \mathrm{ng}$ genomic DNA, was amplified in a final volume of $10 \mu \mathrm{L}$, which contained $10 \times$ PCR buffer $(1 \mu \mathrm{L})$, internal control primers (human growth hormone, $0.1 \mu \mathrm{M})$, dNTP $(1 \mu \mathrm{L}, 200 \mu \mathrm{M})$, Taq DNA polymerase $(0.5 \mu \mathrm{L}, 1 \mathrm{U})$, and primer mixture $(0.5 \mu \mathrm{L}, 10 \mathrm{pmol} / \mathrm{L})$, with sterilized water to reach the final volume. The PCR cycles for amplification were performed after forced denaturation at $95^{\circ} \mathrm{C}$ for 5 min (PE-9600 or PE-9700), with 30 cycles at $95^{\circ} \mathrm{C}$ for $30 \mathrm{~s}, 63^{\circ} \mathrm{C}$ for $50 \mathrm{~s}, 72^{\circ} \mathrm{C}$ for $30 \mathrm{~s}$, and a final holding at a constant $4^{\circ} \mathrm{C}$. The amplification products $(6 \mu \mathrm{L})$ were electrophoresed [1\% gel and $0.5 \times$ TBE buffer $(\mathrm{pH} 8.0)]$ at $8-10 \mathrm{~V} / \mathrm{cm}$ for 5 - 7 minutes in order, and were observed under an ultraviolet transilluminator thereafter.

\subsection{Pathological Diagnosis and Clinical Treatment}

All histopathology slides were diagnosed independently by two pathologists under light microscopy within 4 weeks after the transplantations. For the LRD small intestine transplantations, the recipients were subjected to pathological biopsy through the ileal stoma by endoscope, and the severity was graded into four levels $(0$, I, II, and III), according to the degree of infiltration of inflammatory cells into the lamina propria, the structural changes in the mucous membrane, and apoptosis of the mucosal and crypt epithelia. In the LRD liver transplantations, pathologic biopsies of the recipients were taken by paracentesis, and the severity was graded into four levels $(0$, I, II, and III) under the Banff standard, according to the degree of lymphocytic infiltration of the biliary epithelium and the tunica intima of portal or hepatic veins [14]. Similarly, paracentesis was used in the LRD kidney transplantations, and the severity was graded into four levels ( 0 , I, II, and III) according to the degree of lymphocytic and monocytic infiltration of the glomeruli, nephric tubules, and renal interstitium under the Banff standard [15].

The clinical manifestations of posttransplant rejection included varying degrees of fever, nausea, vomiting, diarrhea, decreased renal function, and leukocytosis or lymphocytosis in the urine. Until the research was completed in May 2010, the 20 recipients who experienced symptoms of posttransplant rejection were followed up. Depending on the clinical symptoms, endoscopy, and biopsy results, they were prescribed standard antifungal, antibacterial, triple immunosuppressive regimen (cyclosporine A [CsA], steroids, and azathioprine or mycophenolate mofetil [MMF]) and anti-lymphocyte globulins therapy in the event of corticoresistance. Immunosuppressive treatment was modified clinically.

\subsection{Detection of Abs against MICA}

Serum samples of living recipients were extracted six times after transplantations at 2, 4, 6, 8, 10, 12 month respectively. Abs to MICA alleles were determined by Luminex flow cutomety, using Terasaki plates. $5 \mu \mathrm{L}$ of LABScreen fluorescence beads and $20 \mu \mathrm{L}$ serum of recipient were dispensed into test wells, incubated for 30 minutes in $20^{\circ} \mathrm{C}-25^{\circ} \mathrm{C}$ at low speed on a platform plate shaker. After that, $150 \mu \mathrm{L}$ of $1 \times$ PBS was added into each well, covered with bellows seal, shaking and centrifuging for 5 minutes at $1300 \times \mathrm{g}$. At last, the plate was washed with buffer. A $100 \mu \mathrm{L}$ quantity of $1 \times$ PE conjugated antihuman IgG was added to each well and incubated for 30 minutes. Finally, $80 \mu \mathrm{L}$ of $1 \times$ PBS was added, and the samples were read using LABScan 100 machine.

Serum samples were tested at 1:100 dilution for Abs against a panel of MICA alleles which covered 8 selected MICA alleles in our study. The raw mean fluorescence intensity (MFI) values were normalized with negative control serum. A reading was considered positive if the fluorescent signal of each bead was above the MFI of negative control sera.

\subsection{Statistical Analysis}

SPSS16.0 for Windows was used to compute the statistical significance of the data among groups. All data met the need of statistical analysis of a small sample size. Balance and comparability between groups was analyzed by Cox Regression. The correlation between the matching rate of the 13 MICA alleles and the levels of posttransplant rejection (pathological classification) were compared using Spearman's analysis. Additionally, two log-Rank analyses were performed to investigate the statistical discrepancy between the MICA matching rate, the pathological classification, and the survival time. Subsequently, a survival curve was plotted. P-values < 0.05 were considered statistically significant. 


\section{Results}

\subsection{HLA Matching between Donors and Recipients}

HLA matching results of the 20 blood samples from the donors-recipient pairs were all half-matching (Figure 1). Almost all HLA-A, HLA-B, and HLA-DR alleles (including those newly published from 1996 to 2004 ) were detected by 96 series of primer amplifications. The samples were considered HLA half-matching based on computer software analysis and interpretation.

\subsection{MICA Matching Rate between Donors and Recipients, and Their Survival Time}

In spite of the same benchmark for HLA half-matching, the matching rate of MICA between recipients and donors was irregular among the different LDR transplantations. The PCR-SSP results between donors and recipients of the 8 MICA genotypes consisting of 13 alleles in the three different LRD organ transplantations are shown in Figure 2. The MICA matching rates were 10/13, 12/13, and 11/13 between the three selected pairs of
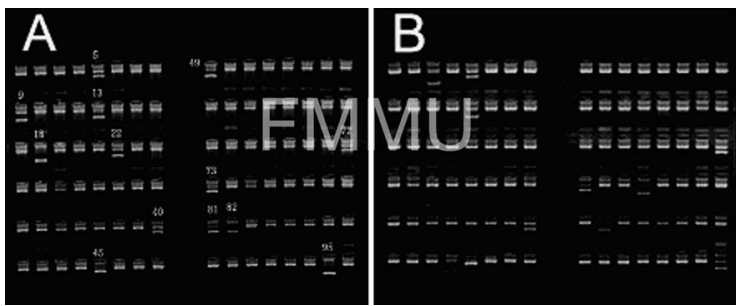

Figure 1. PCR/SSP images of recipient-donor HLA half-matching in one case of LRD small intestine transplantation. The sequence of bands in A (recipient) is consistent with that of $\mathbf{B}$ (donor). The first band was contaminant detection, the 2nd to 25th band covered all HLA-A alleles, the 26th to 73th band covered all HLA-B alleles, and the 74th to 96th band covered all HLA-DR alleles through primers' amplification. Positive bands labeled by numbers meant HLA alleles unmatched (Figure 1(A)).
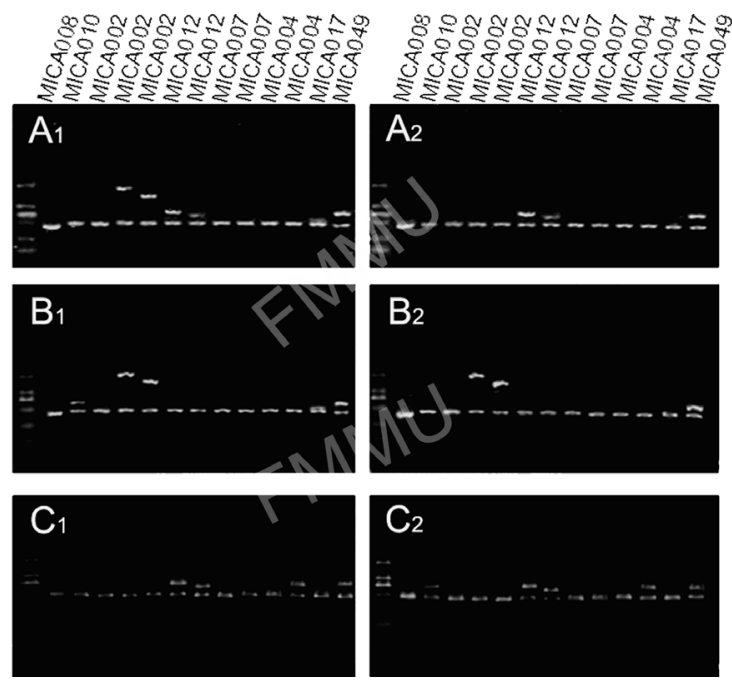

Figure 2. PCR/SSP images of 8 MICA genotypes consisted of 13 alleles between recipients and donors in three different LRD organ transplantations. $\mathbf{A}_{1}$ : 13 MICA alleles of recipient in one case of LRD small intestine transplantation were aligned by the sequence mentioned in text, consistent with that of $\mathbf{A}_{2}, \mathbf{B}_{1}, \mathbf{B}_{2}, \mathbf{C}_{1}, \mathbf{C}_{2} ; \mathbf{A}_{2}$ : 13 MICA alleles matching rate of donor was $10 / 13$ to the recipient; $\mathbf{B}_{\mathbf{1}}, \mathbf{B}_{2}$ : MICA matching rate was $12 / 13$ between recipient and donor in one case of LRD liver transplantation; $\mathbf{C}_{\mathbf{1}}$, $\mathbf{C}_{2}$ : MICA matching rate was $11 / 13$ between recipient and donor in one case of LRD kidney transplantation. 
Recipient-donor samples (Figures 2(A)-(C)). The first vertical band represents the molecular weight standard, with the 13 transversal bands on the bottom representing the 13 selected recipient MICA alleles, which were arranged in sequence as follows: MICA*008, MICA*010, MICA*00201, MICA*00202, MICA*00203, MICA* 01201, MICA*01202, MICA*00701, MICA*00702, MICA*00401, MICA*00402, MICA*017, and MICA*049 from left to right (Figure 2( $\left.\mathbf{A}_{1}\right)$ ). Similarly, 13 MICA alleles of donors were arranged in the same sequence from left to right (Figure 2( $\left.\mathbf{A}_{2}\right)$ ). The results of the MICA matching rates for all 20 donor-recipient pairs, along with their survival times, are presented in Table 2.

Considering 6 as the median of all selected 13 MICA matching rate, the given data were divided into two groups ( $>6 / 13$ and $\leq 6 / 13$ group), and their correlation and survival were analyzed by Log-Rank analysis. Cox Regression showed balance and comparability between groups. No statistically significant difference was observed between the two groups $\left(\mathrm{P}=0.118, \mathrm{P}>0.05, \chi^{2}=2.44\right.$; mean survival time in $>6 / 13$ group $=114.2$ months, 95\% CI: 91.6 - 136.8; mean survival time in $\leq 6 / 13$ group = 28.0 months, 95\% CI: 15.3 - 40.8). Figure 3 shows the survival curve, which indicates different trends between these two groups despite the statistically insignificant difference. Another Log-Rank analysis was used to analyze the correlation between the pathologic classifications (I, II, and III) and survival. A statistically significant difference was observed between the groups $\left(\mathrm{P}=0.05, \mathrm{P}<0.05, \chi^{2}=5.99\right)$. Figure 4 shows the survival curve of the three groups based on pathologic classification.

\subsection{Correlation between MICA Matching Rate and Pathologic Classification}

Spearman's analysis of the correlation between the MICA matching rates and the pathologic classification indicated a negative or inverse relationship (coefficient correlation $=-0.715, \mathrm{P}<0.001, \mathrm{P}<0.05$ ). Hence, the higher the matching rate of the MICA alleles, the lower the pathologic classification.

For example, in LRD small intestine transplantation, apoptosis of mucosal epithelium, infiltration of inflammatory cells into lamina propria, and minimal dysplastic villi in the intestinal mucosa were observed in Level I (Figure 5(A)). In Level II, more serious inflammatory cell infiltration, apoptosis of mucosal epithelium, and dysplastic villi, accompanied by vacuolar degeneration in the basal epithelial cells and a decrease in beaker cells in the glands were observed (Figure 5(B)). Level III involves generous inflammatory cell infiltration into the mesenchyme, significant vasculitis, disappearance of the intestinal villus structure, and denaturation and desquamation of the mucosal epithelium (Figure 5(C)).

Table 2. Patient characteristics and the data of MICA matching rate between recipients and donors, pathological classification and survival.

\begin{tabular}{|c|c|c|}
\hline $\begin{array}{c}\text { Variable, } \mathrm{n}(\%) \\
\text { Total patients }(\mathrm{N}=20)\end{array}$ & $\begin{array}{l}\text { MICA matching rate } \\
\leq 6 / 13(\mathrm{n}=7)\end{array}$ & $\begin{array}{l}\text { MICA matching rate } \\
>6 / 13(\mathrm{n}=13)\end{array}$ \\
\hline Average age (years; SD) & $23.4 \pm 3.7$ & $24.2 \pm 5.6$ \\
\hline \multicolumn{3}{|l|}{ Gender } \\
\hline Male & $5(71 \%)$ & $10(77 \%)$ \\
\hline Female & $2(29 \%)$ & $3(23 \%)$ \\
\hline \multicolumn{3}{|l|}{ Type of graft } \\
\hline Intestine & $2(29 \%)$ & $2(15 \%)$ \\
\hline Liver & $2(29 \%)$ & $4(31 \%)$ \\
\hline Kidney & $3(42 \%)$ & $7(54 \%)$ \\
\hline Mean survival time (months; 95\% CI) & $28.0(15.3-40.8)$ & $114.2(11.5$ - 91.6) \\
\hline \multicolumn{3}{|l|}{ Survival information } \\
\hline Living & $4(57 \%)$ & $2(15 \%)$ \\
\hline Dead & $3(43 \%)$ & $11(85 \%)$ \\
\hline \multicolumn{3}{|l|}{ Pothological classification } \\
\hline $\mathbf{I}$ & $0(0 \%)$ & $7(54 \%)$ \\
\hline II & $4(57 \%)$ & $6(46 \%)$ \\
\hline III & $3(43 \%)$ & $0(0 \%)$ \\
\hline
\end{tabular}

SD: standard deviation. 


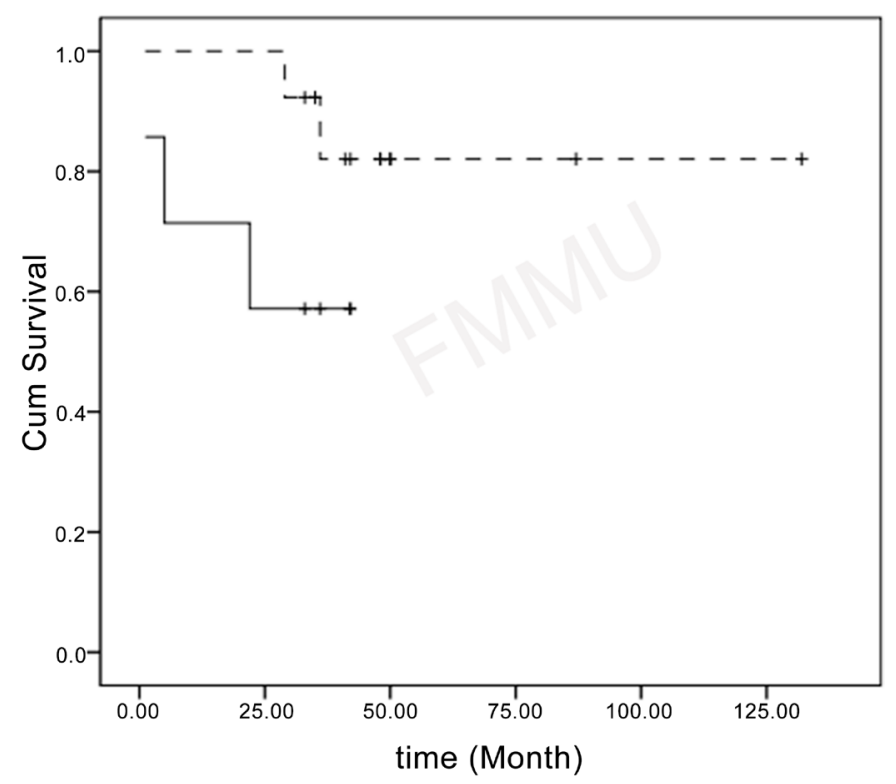

Figure 3. Survival curve of correlation between two groups (MICA matching rate $>6 / 13$ and $\leq 6 / 13$ group) and survival. The dashed line represents the group wherein the MICA matching rate exceeded 6/13. The solid line represents the group in which MICA matching rate was less than or equal to $6 / 13$.

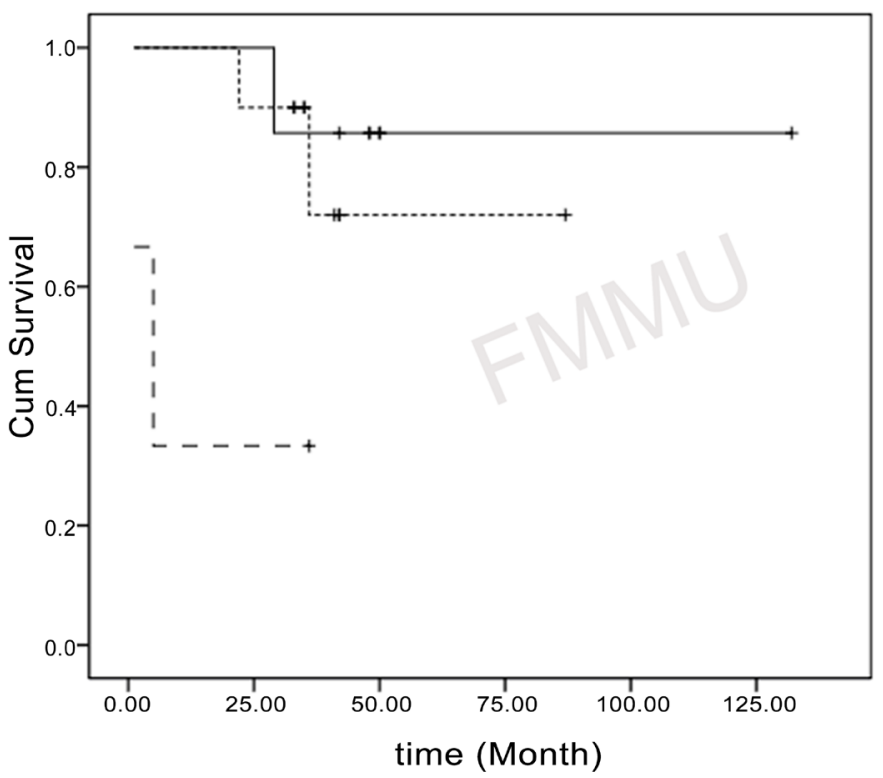

Figure 4. Survival curve of correlation between three groups (three levels in pathological classification: I, II, and III) and survival. The dashed line represents the level III group; the dotted line represents the level II group; the solid line represents the level I group.

\subsection{Abs to MICA Level in Different Period after Transplantations}

Serial samples from these patients were assessed for MFI of MICA Abs to correlate the MICA matching rate, MICA antibodies and posttransplant rejection. We found that the recipients with severe posttransplant rejection (11 patients of pathologic classification Level II/III) showed higher titers. However, the recipients with lighter posttransplant rejection (7 patients of pathologic classification Level I) showed lower tilters. In accord with Abs 
against a panel of MICA antigens (company provided) and Abs to 8 selected MICA alleles in our study, MICA*002, $* 008, * 004, * 007$ and $* 012$ were selected as targets. According to MFI values to selected Abs in the different periods afte transplantations, we also drawed different curves. As shown in Figure 6(A) and Figure 6(B), Abs to MICA MICA*002, *008*004, *007 and *012 showed higher MFI values in group of severe posttransplant rejection, with a peak Abs titer during 5 - 6 months after transplantations. In contrast, Abs to MICA in group of lighter posttransplant rejection showed lower MFI values, without a peak Abs titer during the same time frame (Figure 6(C) and Figure 6(D)).

\section{Discussion}

HLA matching in organ transplantations has positive effect on posttransplant survival; higher HLA mismatches are associated with higher incidences of rejection and worse graft outcomes [16]. Thus, monitoring anti-HLA
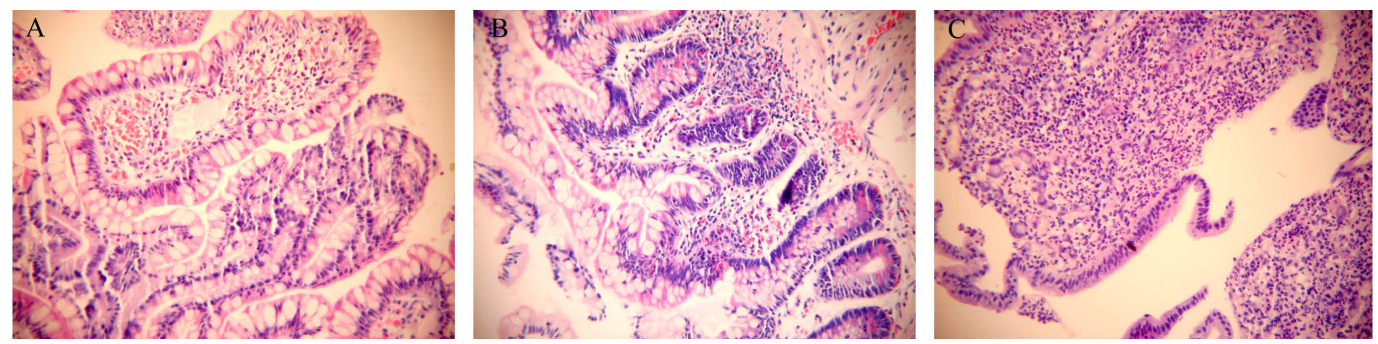

Figure 5. Images of microscopic pathology in three cases of LRD small intestine transplantations (HE stain, 200×). (A) Pathological classification level I; (B) Pathological classification level II; (C) Pathological classification level III.
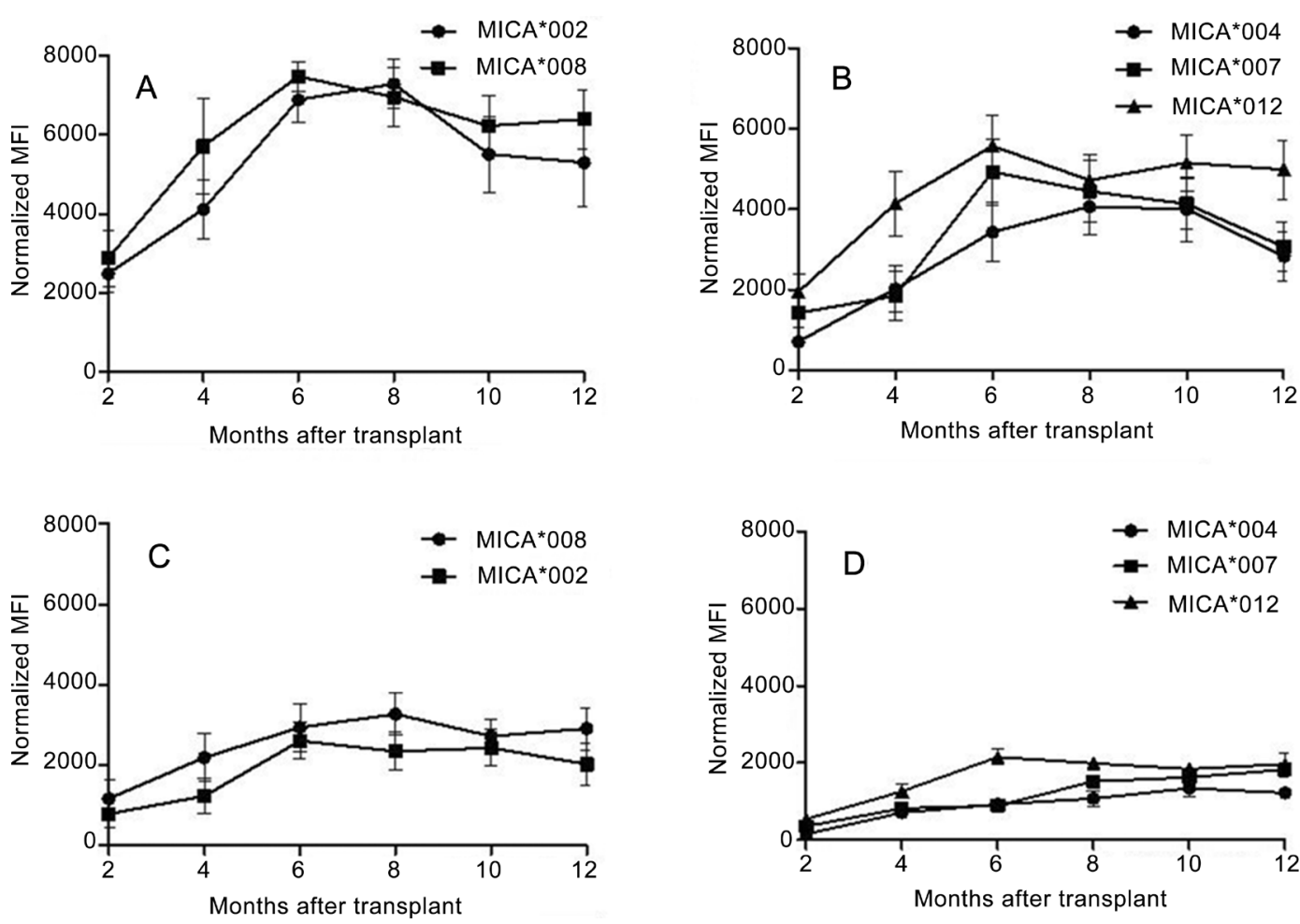

Figure 6. MFI values of MICA antibodies in patients of different pathological classification level. For specific MICA alleles (MICA*002 and *008 in Panel A; MICA*004, *007 and *008 in Panel B), the curve represents the change of Abs titer in normalized MFI after transplantations. Serial monitoring of Abs to MICA alleles indicated that titers of MICA antibodies reached a peak during about 5 - 6 months after transplantations in group of severe rejection (Curves A and B). Curves C and D showed the MFI values and tendency of Abs to MICA in group of lighter posttransplant rejection. 
antibodies would be helpful in predicting the risk of acute and/or chronic rejection [17]. Successive studies have also demonstrated the immune responses accompanying both HLA and/or MICA antibodies to mismatched donor HLA and/or MICA antigens during the postoperative period; therefore, monitoring antibodies to both MICA and HLA could provide important prognostic markers for transplantation [18]-[21]. Although MICA and HLA are similar molecules, the two genomes have been demonstrated to share almost none of the polymorphic residues [22]; however, the response against MICA antigens is, in many ways, similar to the antibody response against HLA antigens. Therefore, MICA could be considered as a separate alloantigenic system that determines the specificity of MICA antibodies in alloantigen-sensitized patients, and the highly polymorphic MICA antigens expressed in transplanted organs may cause posttransplant rejection [23]. Recent studies have highlighted the important role of non-HLA matching in LRD organ transplantations [24]. The gene product of MICA reportedly has a positive effect on posttransplant survival, because MICA-specific antibodies have been detected in recipients [25]. Recipients who are HLA compatible with their donors show better survival and lower incidences of posttransplant rejection when matched additionally for non-classical HLA [26].

HLA half-matching is ideal when transplantation is between parents and children, except for the $25 \%$ chance of HLA complete-matching between siblings in LRD organ transplants, guarantees that the recipient haplotype contains the alleles of 3 of the 6 antigens (two HLA-I and one HLA-II). Although the association between MICA antibodies and posttransplant rejection has been confirmed, little information is available on whether MICA mismatch prevention enhances transplant outcomes.

Based on statistical analysis of a small sample size, 20 precious clinical specimens were collected, including the first case of LRD small intestine transplantation in China. Unified standard of immunosuppressive regimen and pathologic classification was used in procedure of experiment. Balance and comparability existed in groups.

After a serial investigation of the 20 pairs of donor-recipient whole blood samples, which had the same HLA half-matching, our data set indicated that all HLA half-matching pairs were irregular in terms of MICA alleles matching. In clinical observations and follow-ups, the best MICA matching rate was 12/13 in the LRD liver transplants and 11/13 in the kidney transplants. These two recipients, who experienced lesser degrees of posttransplant rejection with optimistic long-term chances of survival, are currently alive at 48 and 42 months, respectively. Two patients who underwent LRD small intestine transplantations in 1999 and 2003 had higher MICA matching rate with their donors are alive at present. On the other hand, two of the recipients who had lower MICA matching rates with their donors died from severe posttransplant rejection. Statistically, if 8 MICA alleles were used as the denominator, the worst MICA matching rate was 5/8 (10/13), whereas the best was $7 / 8$ (10/13). In fact, the two deceased LRD small intestine transplantation cases were matched 4/8 (6/13 and 4/13). Meanwhile, the worst rate in all 20 pairs of donors and recipients was also 4/8 (4/13). Some MICA genetypes that consisted of two or more alleles have assumedly educed immunological effect overall, and different alleles in the same genotype have different functions and meanings. Consequently, there was no MICA matching rate less than 4/13 (four MICA genotypes comprising one allele each). Further studies are needed; however, the data in the current study provide a basis for future studies on the potential role of different MICA alleles in the same genotype in organ transplantations.

The data analysis showed no exact correlations among MICA matching rate, and posttransplant rejection, and survival time. For instance, the first case of LRD small intestine transplantation in China, 1999, whose MICA matching rate with the donor was 10/13 (the best MICA matching rate thus far) has lived, to date, for 11 years, enjoyed a better quality of life, and had minimal posttransplant rejection and a pathological classification of Level I. The fourth case of LRD small intestine transplantation performed in 2003, whose MICA matching rate was also 10/13, has lived for 7 years to date; however, the patient has experienced fever, refractory diarrhea, and malnutrition after the transplantation, with a pathological classification of Level II. Similarly, some of the recipients who had lower MICA matching rates with their donors experienced relatively lesser degrees of posttransplant rejection and/or pathological classification in LRD liver/kidney transplantation. One recipient of an LRD liver transplant, whose MICA matching rate was 7/13 (>6/13 group), experienced a lesser degree of posttransplant rejection (pathological classification of Level I), but died of other complications 29 months after transplantation. In contrast, one recipient of an LRD kidney transplant, whose MICA matching rate was 5/13 ( $\leq 6 / 13$ group), experienced relatively severe posttransplant rejection (pathological classification of Level III), but survived and has been alive for 36 months to date. Overall, based on clinical observations and follow-up visits, posttransplant rejection in LRD liver/kidney is less severe than that in LRD small intestine transplantations. In view of immunity of intestine, we concider that MICA matching have a greater effect on small intestine transplantation than 
others. In our study, several possible reasons for this inconsistency between MICA matching rate, posttransplant rejection, and survival time were considered: First, the errors and extremes contributed by a relatively small sample size and individual differences in responses to immunodepressant; second, the numerous unusual MICA alleles that were not included in the study and other posttransplant complications that affected survival and rejection; and third, the different immunotolerances of different organs.

To cater for the study between MICA matching rate and posttransplant rejection, we also detected MICA antibodies in living recipients. The result showed that the high frequency of MICA (example for MICA*002, *008, *004, *007 and *012) had higher titers of antibodies than others. Based on detection of Abs to MICA in different times after transplantations, we also found that the recipients of severe posttransplant rejection (pathologic classification Level II/III) had higher Abs titers than that of lighter posttransplant rejection. Clinically, the curves we drawed has not strict coincidence with the time and intensity of posttransplant rejection and complication. From the perspective of curves' development, we consider that MICA antibodies have long-term effects on grafts.

In conclusion, we have demonstrated the relationship of MICA matching rate and posttransplant outcomes from the standpoint of pretransplant matching. Our research indicates that better MICA matching rates correspond relatively to less posttransplant rejection and longer survival; therefore, the poor graft survival in our series of HLA-identical LRD organ transplantations could be explained by MICA incompatibility between recipients and donors. Based on our results, detection of MICA matching rates between donors and recipients before clinical transplantations could be used for prognostication of posttransplant outcomes. Closer MICA matching needs to be considered to improve graft outcomes among sensitized recipients.

\section{Financial Support}

This study was supported by the National Natural Science Foundation of China (No. 3203022).

\section{Conflict of Interest}

None.

\section{References}

[1] Sumitran, H.S. (2008) Relevance of MICA and Other Non-HLA Antibodies in Clinical Transplantation. Current Opinion in Immunology, 20, 607-613. http://dx.doi.org/10.1016/j.coi.2008.07.005

[2] Opelz, G. (2005) Non-HLA-Transplantation Immunity Revealed by Lymphocytotoxic Antibodies. Lancet, 365, 15701576. http://dx.doi.org/10.1016/S0140-6736(05)66458-6

[3] Panigrahi, A., Gupta, N., Siddiqui, J.A., et al. (2007) Post Transplant Development of MICA and Anti-HLA Antibodies Is Associated with Acute Rejection Episodes and Renal Allograft Loss. Human Immunology, 68, 362-367. http://dx.doi.org/10.1016/j.humimm.2007.01.006

[4] Bahram, S., Bresnahan, M., Geraghty, D.E. and Spies, T. (1994) A Second Lineage of Mammalian Major Histocompatibility Complex Class I Genes. The Proceedings of the National Academy of Sciences of the United States of America, 91, 6259-6263. http://dx.doi.org/10.1073/pnas.91.14.6259

[5] Petersdorf, E.W., Shuler, K.B., Longton, G.M., Spies, T. and Hansen, J.A. (1999) Population Study of Allelic Diversity in the Human MHC Class I-Related MIC-A Gene. Immunogenetics, 49, 605-612. http://dx.doi.org/10.1007/s002510050655

[6] Zwirner, N.W., Marcos, C.Y., Mirbaha, F., Zou, Y. and Stastny, P. (2000) Identification of MICA as a New Polymorphic Alloantigen Recognized by Antibodies in Sera of Organ Transplant Recipients. Human Immunology, 61, 917-924. http://dx.doi.org/10.1016/S0198-8859(00)00162-2

[7] Zwirner, N.W., Fernandez-Vina, M.A. and Stastny, P. (1998) MICA, a New Polymorphic HLA-Related Antigen, Is Expressed Mainly by Keratinocytes, Endothelial Cells, and Monocytes. Immunogenetics, 47, 139-148. http://dx.doi.org/10.1007/s002510050339

[8] Clatworthy, M., Espeli, M., Torpey, N. and Smith, K. (2010) The Generation and Maintenance of Serum Alloantibody. Current Opinion in Immunology, 22, 669-681. http://dx.doi.org/10.1016/j.coi.2010.08.018

[9] Choy, M.K. and Phipps, M.E. (2010) MICA Polymorphism: Biology and Importance in Immunity and Disease. Trends in Molecular Medicine, 16, 97-106. http://dx.doi.org/10.1016/j.molmed.2010.01.002

[10] Sumitran, H.S., Wilczek, H.E., Holgersson, J. and Soderstrom, K. (2002) Identification of the Nonclassical HLA Mo- 
lecules, Mica, as Targets for Humoral Immunity Associated with Irreversible Rejection of Kidney Allografts. Transplantation, 74, 268-277. http://dx.doi.org/10.1097/00007890-200207270-00019

[11] Li, L., Wadia, P., Chen, R., Kambham, N., Naesens, M., Sigdel, T.K., et al. (2009) Identifying Compartment-Specific Non-HLA Targets after Renal Transplantation by Integrating Transcriptome and “Antibodyome” Measures. Proceedings of the National Academy of Sciences of the United States of America, 106, 4148-4153. http://dx.doi.org/10.1073/pnas.0900563106

[12] Dragun, D. and Hegner, B. (2009) Non-HLA Antibodies Post-Transplantation: Clinical Relevance and Treatment in Solid Organ Transplantation. Contributions to Nephrology, 162, 129-139. http://dx.doi.org/10.1159/000170845

[13] Mizutani, K., Terasaki, P., Rosen, A., Esquenazi, V., Miller, J., Shih, R.N.J., et al. (2005) Serial Ten-Year Follow-Up of HLA and MICA Antibody Production Prior to Kidney Graft Failure. American Journal of Transplantation, 5, 22652272. http://dx.doi.org/10.1111/j.1600-6143.2005.01016.x

[14] Ormonde, D.G., De-Boer, W.B., Kierath, A., Bell, R., Shilkin, K.B., House, A.K., et al. (1999) Banff Schema for Grading Liver Allograft Rejection: Utility in Clinical Practice. Liver Transplantation and Surgery, 5, 261-268. http://dx.doi.org/10.1002/lt.500050418

[15] Solez, K., Axelsen, R.A., Benediktsson, H., Burdick, J.F., Cohen, A.H., Colvin, R.B., et al. (1993) International Standardization of Criteria for the Histologic Diagnosis of Renal Allograft Rejection: The Banff Working Classification of Kidney Transplant Pathology. Kidney International, 44, 411-421. http://dx.doi.org/10.1038/ki.1993.259

[16] Paramesh, A.S., Zhang, R., Baber, J., Yau, C.L., Slakey, D.P., Killackey, M.T., et al. (2010) The Effect of HLA Mismatch on Highly Sensitized Renal Allograft Recipients. Clinical Transplantation, 24, E247-E252. http://dx.doi.org/10.1111/j.1399-0012.2010.01306.x

[17] Panigrahi, A., Deka, R., Bhowmik, D., Tiwari, S.C. and Mehra, N.K. (2004) Immunological Monitoring of Posttransplant Allograft Sensitization Following Living Related Donor Renal Transplantation. Transplantation Proceedings, 36, 1336-1339. http://dx.doi.org/10.1016/j.transproceed.2004.05.072

[18] Hourmant, M., Cesbron, G.A., Terasaki, P.I., Mizutani, K., Moreau, A., Meurette, A., et al. (2005) Frequency and Clinical Implications of the Development of Donor-Specific and Non-Donor-Specific HLA Antibodies after Kidney Transplantation. Journal of the American Society of Nephrology, 16, 2804-2812. http://dx.doi.org/10.1681/ASN.2004121130

[19] Terasaki, P.I., Ozawa, M. and Castro, R. (2007) Four-Year Follow-Up of a Prospective Trial of HLA and MICA Antibodies on Kidney Graft Survival. American Journal of Transplantation, 7, 408-415. http://dx.doi.org/10.1111/j.1600-6143.2006.01644.X

[20] Stastny, P., Zou, Y., Fan, Y., Qin, Z. and Lavingia, B. (2009) The Emerging Issue of MICA Antibodies: Antibodies to MICA and Other Antigens of Endothelial Cells. Contributions to Nephrology, 162, 99-106. http://dx.doi.org/10.1159/000170842

[21] Kauke, T., Kaczmarek, I., Dick, A., Schmoeckel, M., Deutsch, M.A., Beiras-Fernandez, A., et al. (2009) Anti-MICA Antibodies Are Related to Adverse Outcome in Heart Transplant Recipients. Journal of Heart and Lung Transplantation, 28, 305-311. http://dx.doi.org/10.1016/j.healun.2009.01.003

[22] Fodil, N., Laloux, L., Wanner, V., Pellet, P., Hauptmann, G., Mizuki, N., et al. (1996) Allelic Repertoire of the Human MHC Class IMICA Gene. Immunogenetics, 44, 351-357. http://dx.doi.org/10.1007/BF02602779

[23] Hankey, K.G., Drachenberg, C.B., Papadimitriou, J.C., Klassen, D.K., Philosophe, B., Bartlett, S.T., et al. (2002) MIC Expression in Renal and Pancreatic Allografts. Transplantation, 73, 304-306. http://dx.doi.org/10.1097/00007890-200201270-00029

[24] Zafar, M.N., Terasaki, P.I., Naqvi, S.A. and Rizvi, S.A. (2006) Non-HLA Antibodies after Rejection of HLA Identical Kidney Transplants. Clinical Transplants, 421-426.

[25] Zou, Y. and Stastny, P. (2009) The Role of Major Histocompatibility Complex Class I Chain-Related Gene A Antibodies in Organ Transplantation. Current Opinion in Organ Transplantation, 14, 414-418. http://dx.doi.org/10.1097/MOT.0b013e32832d835e

[26] Kitcharoen, K., Witt, C.S., Romphruk, A.V., Christiansen, F.T. and Leelayuwat, C. (2006) MICA, MICB, and MHC Beta Block Matching in Bone Marrow Transplantation: Relevance to Transplantation Outcome. Human Immunology, 67, 238-246. http://dx.doi.org/10.1016/j.humimm.2006.02.012 
Scientific Research Publishing (SCIRP) is one of the largest Open Access journal publishers. It is currently publishing more than 200 open access, online, peer-reviewed journals covering a wide range of academic disciplines. SCIRP serves the worldwide academic communities and contributes to the progress and application of science with its publication.

Other selected journals from SCIRP are listed as below. Submit your manuscript to us via either submit@scirp.org or Online Submission Portal.
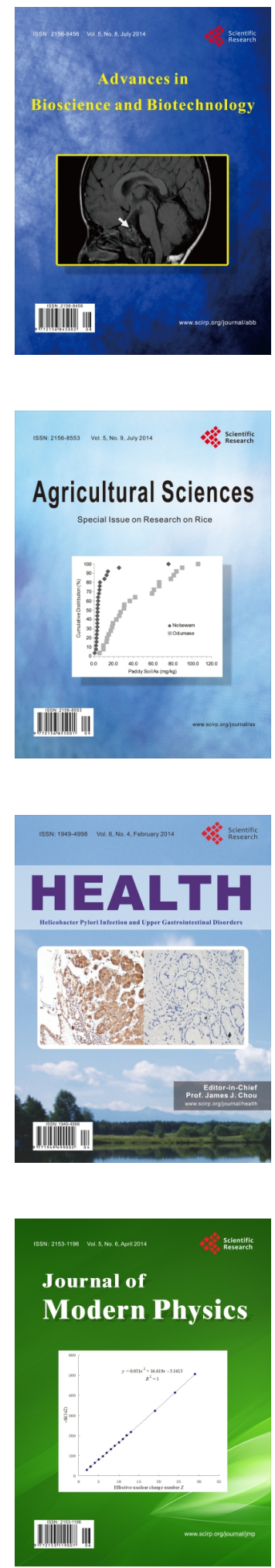
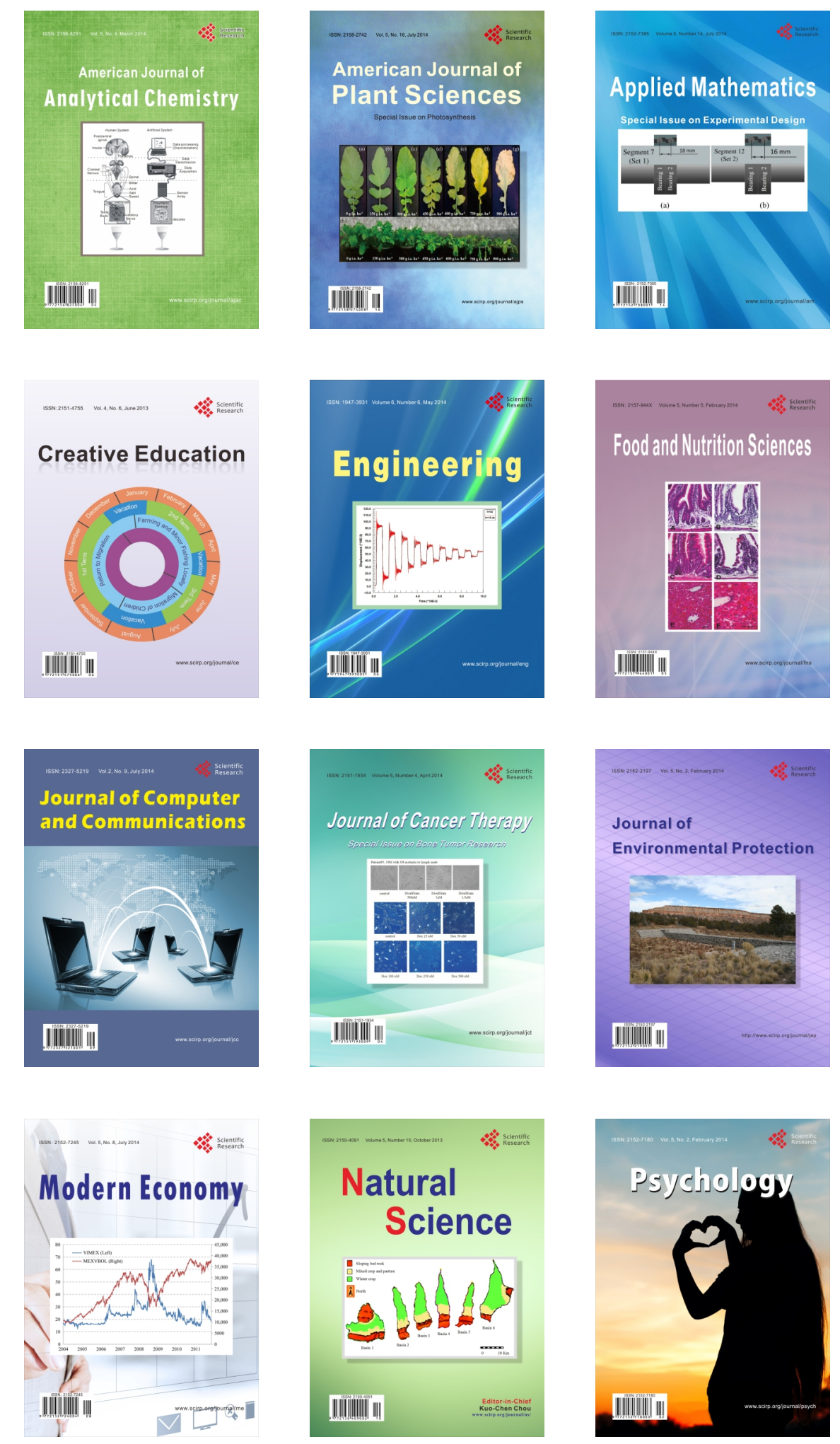